\title{
Article
}

\section{The Anti-Inflammatory Effect of Hydrogen Gas Inhalation and Its Influence on Laser-Induced Choroidal Neovascularization in a Mouse Model of Neovascular Age-Related Macular Degeneration}

\author{
I-Chia Liang 1,2®, Wen-Chin Ko ${ }^{3,4}{ }^{\text {, Yu-Jou Hsu }}{ }^{5}$, Yi-Ru Lin ${ }^{6}$, Yun-Hsiang Chang ${ }^{1}$, Xv-Hui Zong ${ }^{7}$, Pei-Chen Lai ${ }^{8}$, \\ Der-Chen Chang ${ }^{9}$ and Chi-Feng Hung ${ }^{3,5,10, * \mathbb{D}}$
}

check for updates

Citation: Liang, I.-C.; Ko, W.-C.; Hsu, Y.-J.; Lin, Y.-R.; Chang, Y.-H.; Zong, X.-H.; Lai, P.-C.; Chang, D.-C.; Hung, C.-F. The Anti-Inflammatory Effect of Hydrogen Gas Inhalation and Its Influence on Laser-Induced Choroidal Neovascularization in a Mouse Model of Neovascular Age-Related Macular Degeneration. Int. J. Mol. Sci. 2021, 22, 12049. https://doi.org/10.3390/ ijms222112049

Academic Editors: Ana Raquel Santiago and Raquel Boia

Received: 12 October 2021 Accepted: 4 November 2021 Published: 7 November 2021

Publisher's Note: MDPI stays neutral with regard to jurisdictional claims in published maps and institutional affiliations.

Copyright: (c) 2021 by the authors. Licensee MDPI, Basel, Switzerland. This article is an open access article distributed under the terms and conditions of the Creative Commons Attribution (CC BY) license (https:/ / creativecommons.org/licenses/by/ $4.0 /)$.
1 Department of Ophthalmology, Tri-Service General Hospital, National Defense Medical Center, Taipei 11490, Taiwan; ysonyaliang@gmail.com (I.-C.L.); yun.siang@me.com (Y.-H.C.)

2 Ph.D. Program in Nutrition and Food Science, Fu Jen University, New Taipei City 24205, Taiwan

3 School of Medicine, Fu Jen Catholic University, New Taipei City 24205, Taiwan; 086938@mail.fju.edu.tw

4 Division of Cardiac Electrophysiology, Department of Cardiovascular Center, Cathay General Hospital, Taipei 10630, Taiwan

5 Graduate Institute of Biomedical and Pharmaceutical Science, Fu Jen Catholic University, New Taipei City 24205, Taiwan; s16179263@gmail.com

6 Department of Ophthalmology, Cathay General Hospital, Taipei 10630, Taiwan; yirulin83088@gmail.com

7 Tsung Cho Chang Laboratory, College of Medicine, Fu-Jen Catholic University, New Taipei City 24205, Taiwan; 054317@mail.fju.edu.tw

8 Institute of Biochemistry and Molecular Biology, College of Medicine, National Taiwan University, Taipei 100233, Taiwan; peggylai1116@gmail.com

9 Department of Mathematics and Statistics and Department of Computer Science, Georgetown University, Washington, DC 20057, USA; chang@georgetown.edu

10 School of Pharmacy, Kaohsiung Medical University, Kaohsiung 80708, Taiwan

* Correspondence: skin@mail.fju.edu.tw; Tel.: +886-2-29052171

Abstract: Background: Age-related macular degeneration (AMD) is a leading cause of blindness in the elderly. Choroidal neovascularization (CNV) is the major pathologic feature of neovascular AMD. Oxidative damages and the ensuing chronic inflammation are representative of trigger events. Hydrogen gas $\left(\mathrm{H}_{2}\right)$ has been demonstrated as an antioxidant and plays a role in the regulation of oxidative stress and inflammation. This experiment aimed to investigate the influence of $\mathrm{H}_{2}$ inhalation on a mouse model of CNV. Methods: Laser was used to induce CNV formation. C57BL/6J mice were divided into five groups: the control group; the laser-only group; and the $2 \mathrm{~h}, 5 \mathrm{~h}$, and $2.5 \mathrm{~h} / 2.5 \mathrm{~h}$ groups that received laser and $\mathrm{H}_{2}$ inhalation ( $21 \%$ oxygen, $42 \%$ hydrogen, and $37 \%$ nitrogen mixture) for $2 \mathrm{~h}, 5 \mathrm{~h}$, and $2.5 \mathrm{~h}$ twice every day, respectively. Results: The severity of CNV leakage on fluorescence angiography showed a significant decrease in the $\mathrm{H}_{2}$ inhalation groups. The mRNA expression of hypoxia-inducible factor 1 alpha and its immediate downstream target vascular endothelial growth factor (VEGF) showed significant elevation after laser, and this elevation was suppressed in the $\mathrm{H}_{2}$ inhalation groups in an inhalation period length-related manner. The mRNA expression of cytokines, including tumor necrosis factor alpha and interlukin-6, also represented similar results. Conclusion: $\mathrm{H}_{2}$ inhalation could alleviate $\mathrm{CNV}$ leakage in a laser-induced mouse $\mathrm{CNV}$ model, and the potential mechanism might be related to the suppression of the inflammatory process and VEGF-driven CNV formation.

Keywords: age-related macular degeneration; choroidal neovascularization; hydrogen gas

\section{Introduction}

Age-related macular degeneration (AMD), the leading cause of blindness in elderly people aged over 60 , is estimated to have an increasing prevalence globally as a consequence 
of exponential population growth, increase in life expectancy, and falling death rates [1-3]. The prevalence of AMD increases exponentially with rising age, which does not differ between males and females $[2,4,5]$. Across racial populations, there is a higher prevalence of AMD in Europeans than in Asians and Africans, while there is no difference between Asians and Africans. Europeans have a higher prevalence of the geographic atrophy subtype than Africans, Asians, and Hispanics. Between geographical regions, AMD was less prevalent in Asia than in Europe and North America [2]. Increasing age and genetic factors play important roles in the development of AMD, while other risk factors, including smoking, obesity, a higher body mass index, and metabolic syndromes, such as dyslipidemia, hypertension, and hyperglycemia, are reported to be associated with higher prevalence, more progression, and increased severity of AMD [1,2,6-8]. AMD stems from accumulation of drusen, the lipoprotein-rich deposits underneath retinal pigment epithelium (RPE) with pigmentary changes and/ or thickened overlying Bruch's membrane. Progressive drusen accumulation results in further inflammation and alterations of RPE as the disease progresses. Advanced AMD is classified to be of the dry (atrophic) or wet (neovascular) type. Advanced dry AMD is characterized by progressive atrophic changes in the RPE and overlying neurosensory retina with an eventual development of geographic atrophy. Proliferation of choroidal neovascularization (CNV) underneath the neurosensory retina contributes to wet AMD [7,9]. Micronutrient supplements may be beneficial for intermediate and advanced AMD. The AREDS study showed a reduction in the progression from intermediate AMD to advanced AMD with a daily formula of $500 \mathrm{mg}$ vitamin $\mathrm{C}$, $80 \mathrm{mg}$ zinc, $400 \mathrm{IU}$ vitamin E, $2 \mathrm{mg}$ copper, and $15 \mathrm{mg}$ beta carotene. A similar effect was observed in the AREDS2 study, with a replacement of beta carotene with $10 \mathrm{mg}$ lutein and $2 \mathrm{mg}$ zeaxanthin $[10,11]$. Lifestyle modification is also recommended to inhibit the progression of AMD [12,13].

Disrupted regulation of angiogenesis is the main pathogenesis of CNV. Vascular endothelial growth factor (VEGF) has been identified as a critical mediator of pathologic neovascularization. The level of VEGF elevates when damage, hypoxia, and ischemia occur. VEGF acts by promoting endothelial cell proliferation and migration, and it is the main regulator of downstream factors. At present, VEGF-targeted treatment is the mainstream treatment for neovascular AMD $[9,14]$. However, the proceeding inflammation and subsequent atrophic changes also play important roles. Increased VEGF alone may not be enough to bring about CNV development, which implies that the VEGF-driven pathways are only part of the complex machinery regulation [15]. VEGF is constitutively produced in the eye and is essential for normal physiology. The adverse effects related with chronic VEGF suppression occur if the loss of pro-survival and neuroprotective capacities of VEGF happen [16]. VEGF-independent regulation of ocular angiogenesis, including neuron survival promotion or immune regulation, is currently under evaluation and is considered an important alternative treatment [17].

Hydrogen gas, an inert gas, has been reported by Ohsawa et al. in 2007 [18] to be an efficient antioxidant in combating oxidative brain injury when administered by inhalation. This finding raises the interest and attracts the attention of various medical communities. Its benefits in several ophthalmic disease models, including retinal ischemia/reperfusion injury, retinal vein occlusion, and endotoxin-induced uveitis, have been evaluated [19-21]. However, its role in a laser-induced AMD animal model has not been evaluated yet.

\section{Results}

2.1. Color Fundus Photography (CFP) and Fluorescence Angiography (FA) Analysis of the Effects of Hydrogen Gas Inhalation on Laser-Induced CNV $(n=3)$

Four spots of laser photocoagulation per eye were performed to induce $\mathrm{CNV}$ formation in C57BL/6J mice on Day 5. Hydrogen inhalation was given since Day 1 as pre-treatment and was continued after laser until Day 15, the end of the experiment. CFP and FA results on both Day 10 and Day 15 are shown in Figure 1a and a. FA leakage scores for each of the four laser spots in each eye were plotted and calculated for all groups. The results of the FA leakage scores on both Day 10 and Day 15 are shown in Figures $1 \mathrm{~b}$ and $2 \mathrm{~b}$ and reveal that 
hydrogen inhalation led to a significant reduction in the FA leakage scores when compared to those without hydrogen inhalation. Moreover, the effect was inhalation time related.

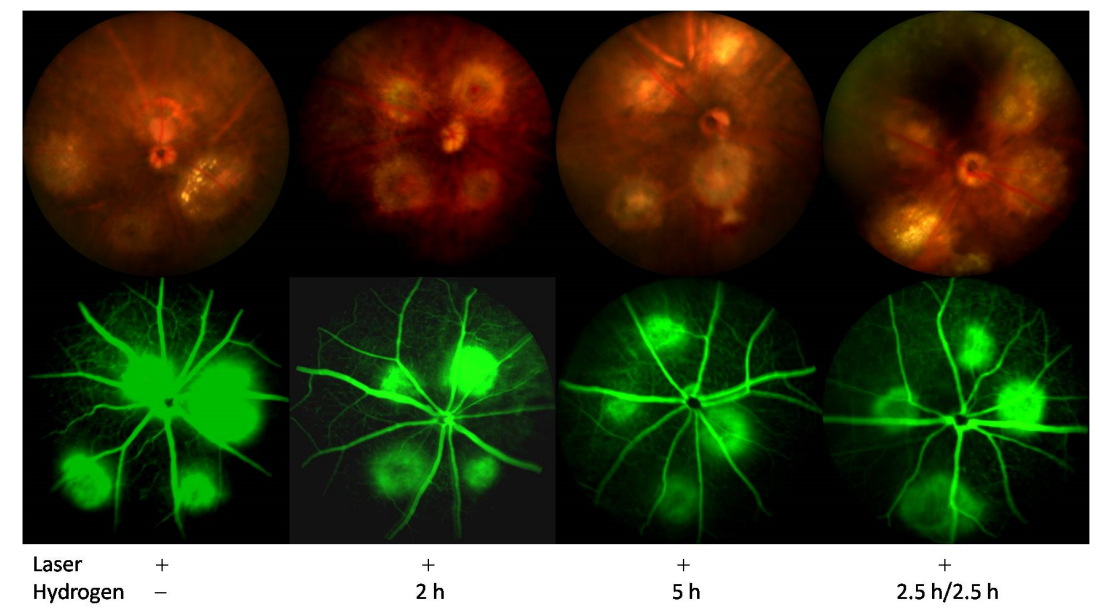

(a)

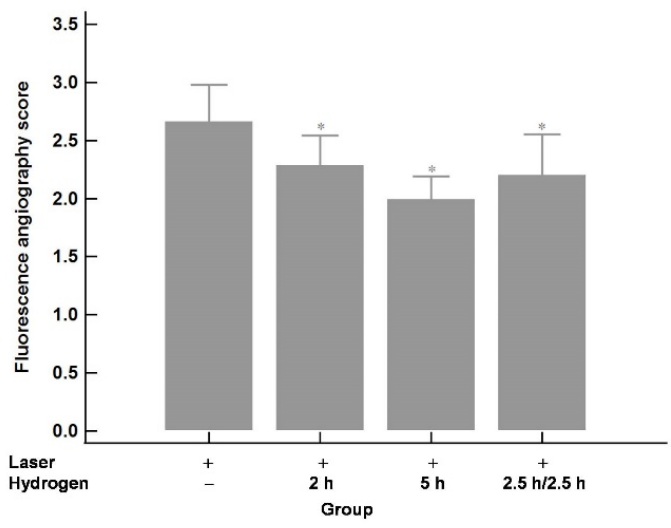

(b)

Figure 1. Day 10 (5 days after laser photocoagulation). (a) CFP and FA. (b) FA leakage scores. Significantly lower FA leakage scores were shown after the hydrogen inhalation compared to those without inhalation and the effect was inhalation period related. ${ }^{*} p<0.05$ compared with the laser+/hydrogen - group.

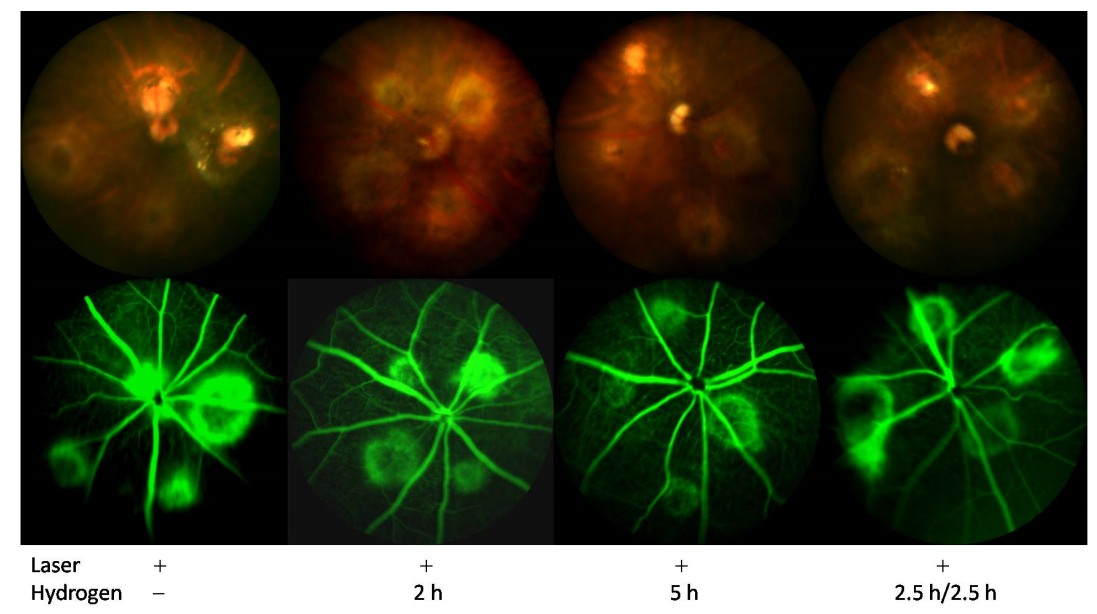

(a)

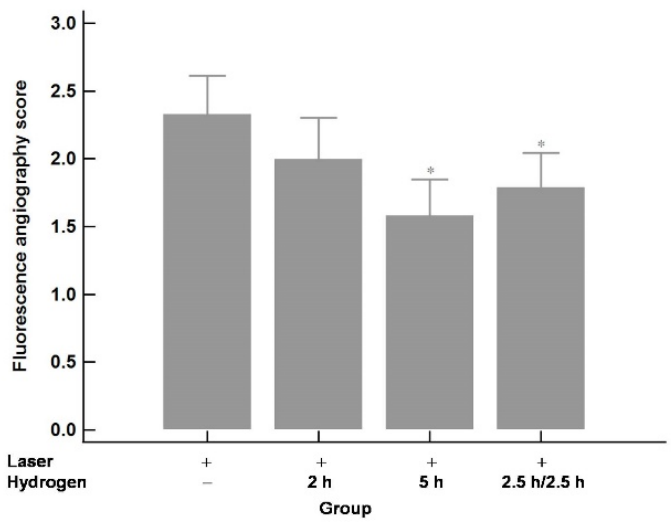

(b)

Figure 2. Day 15 (10 days after laser photocoagulation). (a) CFP and FA. (b) FA leakage scores. Significantly lower FA leakage scores were shown after the hydrogen inhalation compared to those without inhalation and the effect was inhalation period related. * $p<0.05$ compared with the laser+/hydrogen - group.

2.2. Histology, Immunofluorescence Staining, and the Effect of Hydrogen as Inhalation on the Reduction in Phosphorylation of the VEGF Receptor

Hematoxylin-eosin (HE) staining of the CNV is shown in Figure 3 and reveals almost no RPE coverage over the CNV tissue in the laser-only group and more RPE coverage over the $\mathrm{CNV}$ tissue after hydrogen inhalation. A longer inhalation time resulted in more RPE coverage. The CNV tissue was revealed to be spindle-shaped in the laser-only group and became flattened after hydrogen inhalation. 

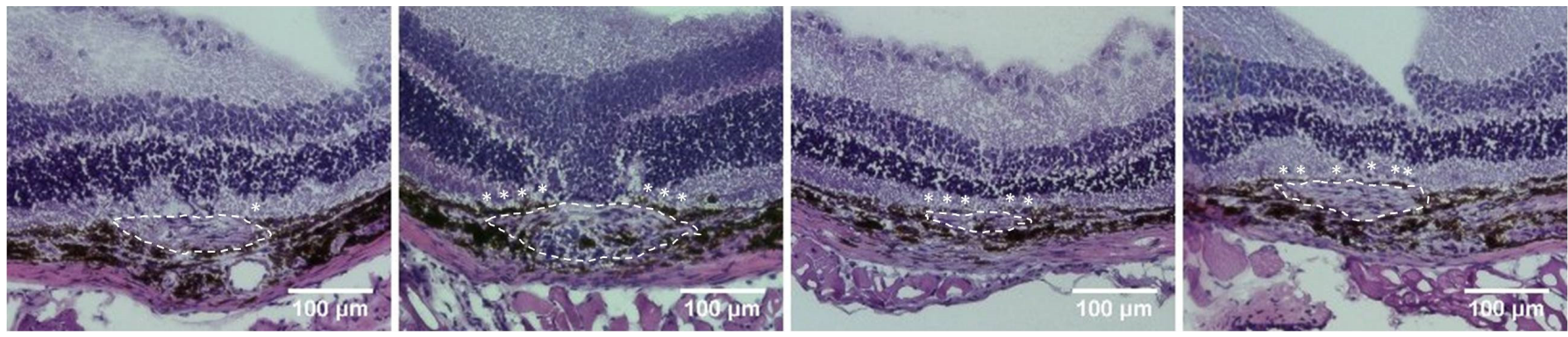

Figure 3. H\&E staining on Day 15 (10 days after laser photocoagulation). Left to right: Laser-only group, $2 \mathrm{~h}$ group, $5 \mathrm{~h}$ group, and $2.5 \mathrm{~h} / 2.5 \mathrm{~h}$ group. The shape of the CNV (white dotted line) became flattened after hydrogen inhalation. More RPE coverage (dark-pigmented tissue labeled with an asterisk) over the CNV tissue was also noted after hydrogen inhalation.

Immunofluorescence staining is showed in Figure 4. The phosphorylation of VEGF receptor (phospho-VEGF receptor, pVEGFR) decreased after hydrogen inhalation.

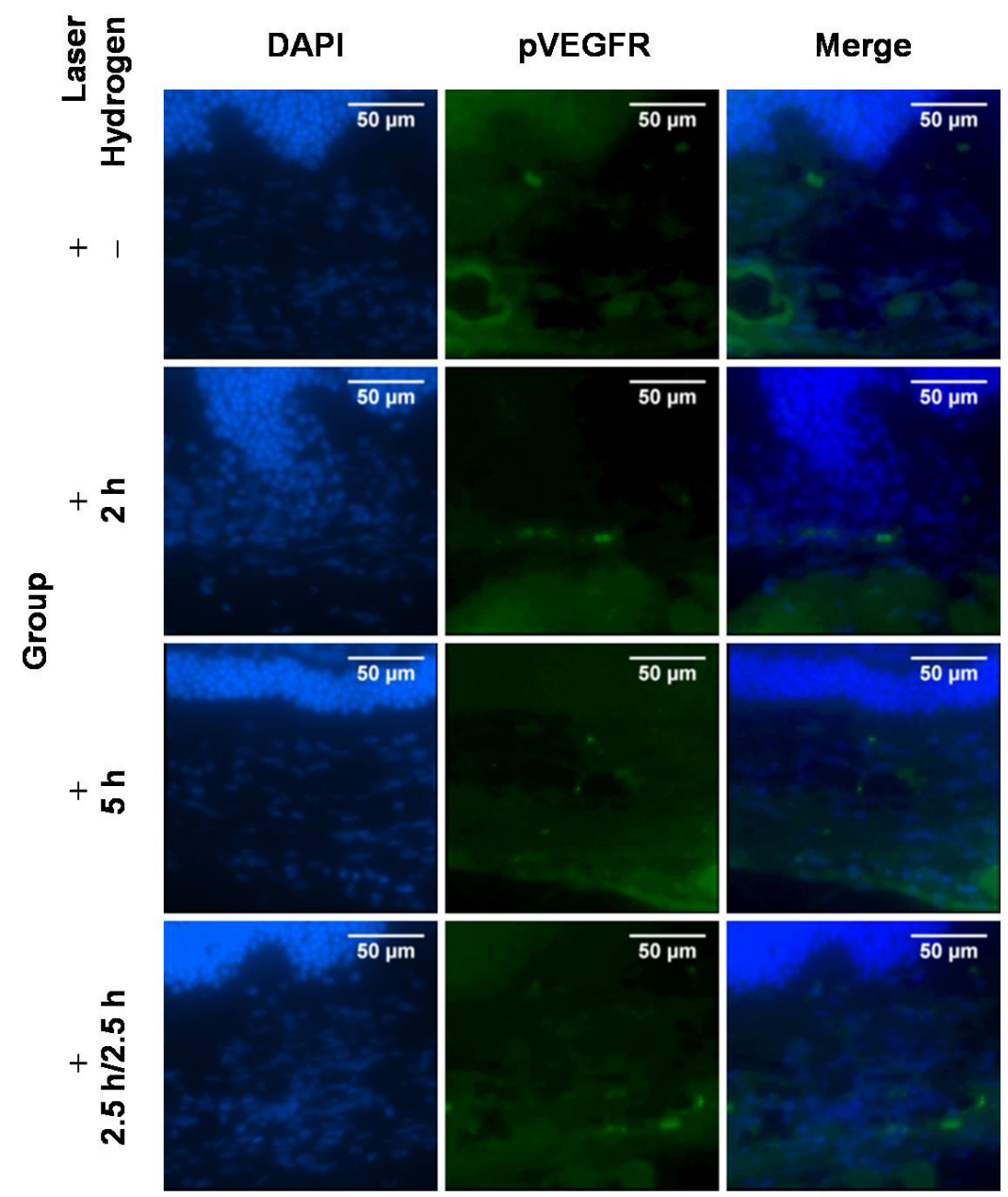

Figure 4. Immunofluorescence staining and the expression of pVEGFR on Day 15 (10 days after laser photocoagulation).

2.3. Hydrogen Gas Inhalation Downregulates the mRNA Expression of Hypoxia-Inducible Factor 1 alpha $(H I F-1 \alpha)$ and Its Immediate Downstream Target VEGF in Laser-Induced CNV $(n=3)$

To understand the mRNA expression after CNV induction and hydrogen gas inhalation, qRT-PCR was used. The results are shown in Figure 5. The expression of HIF-1 $\alpha$ and VEGF increased significantly after laser photocoagulation compared with those of the 
control group (no laser or hydrogen inhalation). Hydrogen inhalation effectively downregulated the mRNA expression of HIF- $1 \alpha$ and VEGF. The effect was more significant in the $5 \mathrm{~h}$ group (a longer inhalation time of $5 \mathrm{~h}$ per day) compared to the $2 \mathrm{~h}$ group (a shorter inhalation time of $2 \mathrm{~h}$ per day). The effect was similar between the $5 \mathrm{~h}$ group and the $2.5 \mathrm{~h} / 2.5 \mathrm{~h}$ group, which indicated that interrupted inhalation could achieve a similar effect as continuous inhalation.

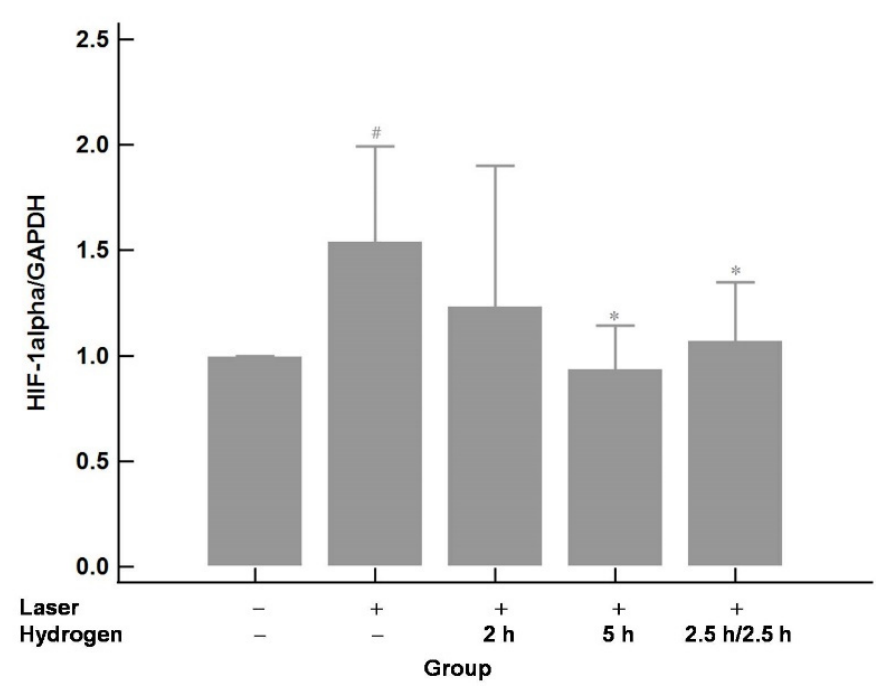

(a)

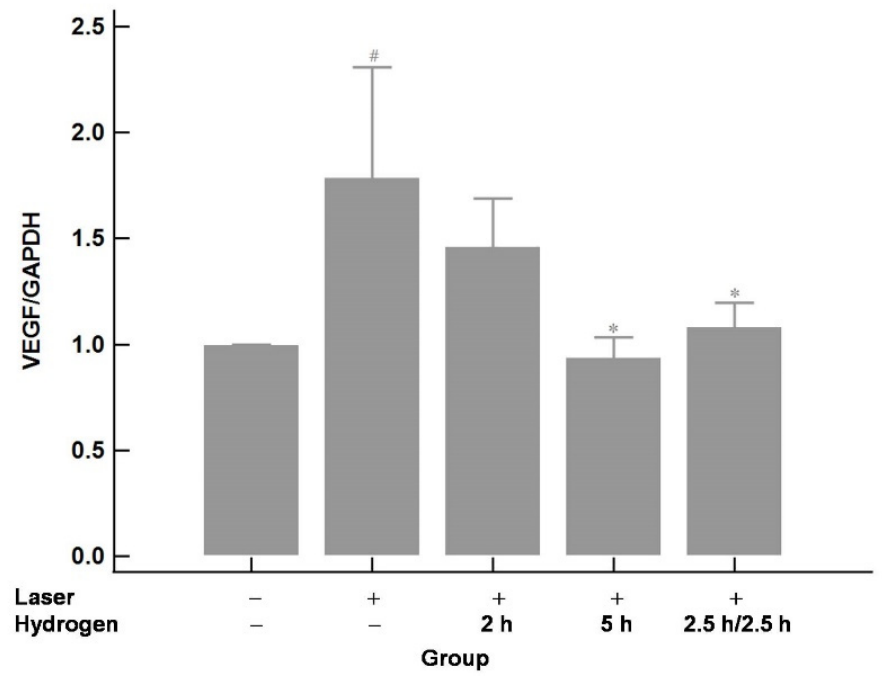

(b)

Figure 5. The mRNA expression of HIF- $1 \alpha$ (a) and VEGF (b). The expression of HIF-1 $\alpha$ and VEGF increased after laser photocoagulation compared with those of the control (no laser or hydrogen inhalation). The elevated HIF- $1 \alpha$ and VEGF expression was downregulated by hydrogen inhalation. The effect was similar between the $2.5 \mathrm{~h} / 2.5 \mathrm{~h}$ and $5 \mathrm{~h}$ groups and showed to be less effective in the $2 \mathrm{~h}$ group. \# $p<0.05$ compared with the control (laser-/hydrogen - ) group; * $p<0.05$ compared with the laser+/hydrogen - group.

2.4. Hydrogen Gas Inhalation Reduces the mRNA Levels of Tumor Necrosis Factor Alpha (TNF- $\alpha$ ) and Interlukin-6 (IL-6) $(n=3)$

The mRNA expression of pro-inflammatory mediators-TNF- $\alpha$ and IL- 6 were assayed by qRT-PCR and are shown in Figure 6. The expression of TNF- $\alpha$ and IL- 6 revealed significant elevation after laser photocoagulation compared with those of the control group (no laser or hydrogen inhalation). This elevation could be effectively downregulated by hydrogen inhalation. The effects of the $5 \mathrm{~h}$ and $2.5 \mathrm{~h} / 2.5 \mathrm{~h}$ groups were about the same and were better than those of the $2 \mathrm{~h}$ group. 


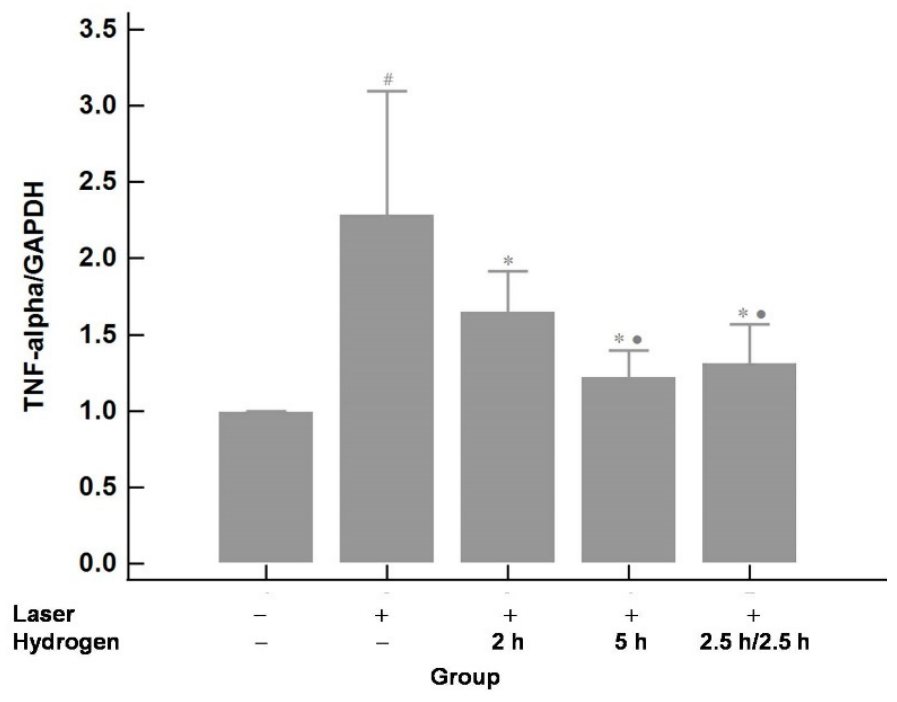

(a)

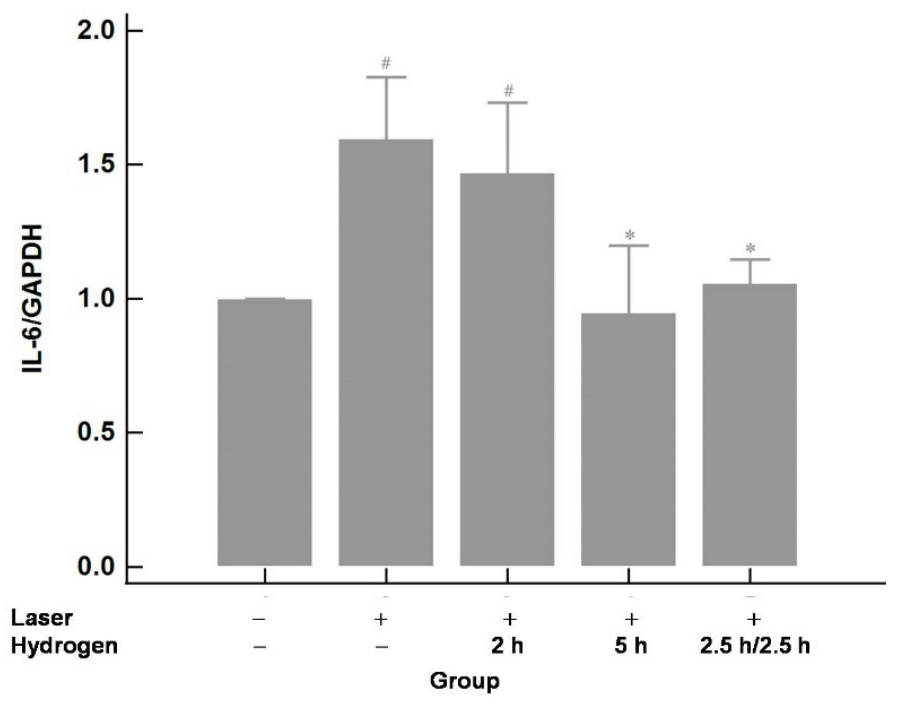

(b)

Figure 6. The mRNA expression of TNF- $\alpha(\mathbf{a})$ and IL-6 (b). The mRNA levels of TNF- $\alpha$ and IL-6 were upregulated after laser photocoagulation compared with those of the control (no laser or hydrogen inhalation). The upregulation could be suppressed by hydrogen inhalation. The effects of the $2.5 \mathrm{~h} / 2.5 \mathrm{~h}$ and $5 \mathrm{~h}$ groups were similar and were more effective than the $2 \mathrm{~h}$ group. \# $p<0.05$ compared with the control (laser $-/$ hydrogen - ) group; ${ }^{*} p<0.05$ compared with the laser+/hydrogen-group; $\bullet p<0.05$ compared with the laser+/hydrogen $2 \mathrm{~h}$ group.

\section{Discussion}

This study showed that hydrogen gas administered via inhalation could protect the sensory retina after the injury of Bruch's membrane disruption, and the following CNV formation was revealed. We found that hydrogen gas could inhibit the inflammation of an injured retina after Bruch's membrane disruption, suppress CNV development, and decrease the leakage of the CNV.

AMD is regarded as a disease of complex multifactorial mechanisms, with aging being one of the main risk factors. While risk factors such as aging and genetic susceptibility are strong and non-modifiable, other risk factors, including diet, smoking, and metabolic disturbances, are modifiable to some extent [22]. Neovascular AMD, predisposed by a dry AMD with continuous progression of RPE atrophy, is characterized by the formation of CNV.

We demonstrated that the leakage of CNV could be significantly decreased by hydrogen gas inhalation. The effect showed inhalation time dependency.

The histological examination of surgically excised CNV from AMD patients showed that the CNV is composed of the vascular component (endothelial cells, pericytes, and precursors of endothelial cells) and the extravascular component (glial cells, RPE cells, fibroblasts, and inflammatory cells, including macrophages, lymphocytes, granulocytes, and foreign body giant cells) [23-25]. Consequently, both inflammation and angiogenesis are involved in the development of CNV.

VEGF has been identified as one of the critical mediators of pathologic neovascularization and its role in ocular angiogenesis has been evaluated in detail [14,26]. VEGF is essential in the initial development of CNV, as the inciting stimulus involved in the proliferation and migration of endothelial cells. RPE cells, ganglion cells, retinal neurons, Müller cells, and immune cells, such as macrophages and monocytes, secrete VEGF in response to hypoxic and inflammatory stimuli [26-29]. The response to hypoxia is mediated by HIF, a family of transcription regulators that regulates the genes involved in the response to hypoxia, including VEGF. HIF- $1 \alpha$ is the inducible subunit of the HIF-1 transcription factor and has been discovered to be present in active CNV specimens. It plays an important 
role in hypoxia signaling during the development and progression of vision-threatening production of CNV [30,31].

At present, based on the ideas of VEGF as the main driver of angiogenesis in CNV, the gold standard therapy for neovascular AMD involves intravitreal administration of VEGF inhibitors. The agents used clinically include bevacizumab, ranibizumab, aflibercept, and brolucizumab. In our present experiment, the mRNA expression of HIF- $1 \alpha$ and VEGF could be successfully inhibited by hydrogen gas inhalation in an inhalation time-related manner. Hydrogen gas inhalation has been shown to alleviate retinal edema and promote retinal function recovery in branched retinal vein occlusion rat model via reducing VEGF expression [19]. Our results revealed that not just VEGF but the upstream translation factor HIF could also be inhibited by hydrogen gas inhalation.

Anti-VEGF pharmacotherapy could successfully inhibit CNV activity and achieve resolution of leakage of blood vessels and hemorrhage in the macula associated with $\mathrm{CNV}$ but is not enough to eradicate $\mathrm{CNV}$ and cure the disease. CNV persists with only partial regression or recurs years later $[17,32]$. Moreover, a subset of patients was found to be non-responsive to anti-VEGF therapy $[33,34]$. As such, VEGF-driven pathways are only a part of the complex machinery regulating angiogenesis in the eye. Regulating ocular angiogenesis other than VEGF is the current goal in the treatment of neovascular AMD.

Macrophages and numerous cytokines have been known to be important players in regulating ocular angiogenesis through multiple mechanisms. Macrophages are critical for the proper retinal vascular remodeling and also play pivotal roles in modulating retinal neovascularization $[17,35,36]$. Depletion of macrophage activity could decrease both the size and leakage of CNV [37]. Leukocytes would be recruited under hypoxia and the increasing macrophages in broken Bruch's membrane elicit the production of TNF- $\alpha$ and the synthesis of ILs as well as stimulate chemokines production from RPE cells [38]. TNF- $\alpha$ was found to be the major cytokine responsible for the macrophage-derived angiogenesis [39]. A nearly five-fold increase in the prevalence of neovascular AMD was noted in patients with blood monocytes expressing higher TNF- $\alpha$ mRNA levels [40]. TNF receptor inhibitor was found to be able to inhibit the blood-retinal barrier breakdown in rat models of inflammation and diabetic retinopathy [41,42]. Angiogenesis-related effects and induction of ocular inflammation are two of the most important effects of IL-6 in the eye [43]. High levels of IL-6 in the blood of patients with neovascular AMD are shown to be positively correlated with disease progression [44]. Despite playing roles in the initial stage of CNV, IL-6 expressed by activated macrophages has been noted to be increased in the CNV lesion of neovascular AMD and that the inhibition of IL-6 signaling can suppress subretinal fibrosis [45,46], which is an important manifestation of end-stage AMD. Targeting IL-6 and the corresponding signaling pathway would bring us close to not only treating $\mathrm{CNV}$ but also preventing subretinal fibrosis and eventual scarring of the macula.

Hydrogen gas inhalation has been proven to decrease the levels of inflammatory cytokines, including TNF- $\alpha$, IL-1 $\beta$, and IL-6, in ischemia/reperfusion injury or the retina, liver, and brain $[20,47,48]$. In our current experiment, the gene expression of TNF- $\alpha$ and IL- 6 could be effectively suppressed by hydrogen inhalation. An inhalation time-dependent effect was also revealed.

The main finding of the current experiment demonstrated that hydrogen inhalation could (1) decrease the leakage of CNV; (2) suppress the VEGF-dependent pathway of CNV formation via downregulation of VEGF and HIF- $1 \alpha$; and (3) inhibit the VEGF-independent pathway via restraining the expression of TNF- $\alpha$ and IL-6. Moreover, the observation that the longer the time of the treatment is, the better the effect is, confirmed an inhalation time-related manner.

\section{Materials and Methods}

\subsection{Animals}

Four to six weeks of age C57BL/6J mice were obtained from the National Biotechnology Research Park, Taipei, Taiwan. 
The mice were divided into five groups as follows: (1) the control group received neither laser nor hydrogen gas inhalation; (2) the laser-only group received laser but no hydrogen gas inhalation; (3) the $2 \mathrm{~h}$ group received laser and a continuous $2 \mathrm{~h}$ hydrogen gas inhalation every day; (4) the $5 \mathrm{~h}$ group received laser and a continuous $5 \mathrm{~h}$ hydrogen gas inhalation every day; and (5) the $2.5 \mathrm{~h} / 2.5 \mathrm{~h}$ group received laser and two periods of $2.5 \mathrm{~h}$ hydrogen gas inhalation interrupted by a $3 \mathrm{~h}$ rest every day.

Mice were anesthetized with intraperitoneal (IP) injection of Zoletil ${ }^{\mathrm{TM}} 50$ (zolazepam + tiletamine) and rompun 20 (xyalzine) in a 3:2 mixture, $1 \mathrm{uL} / 1 \mathrm{~g}$, and the pupils were dilated with $0.5 \%$ phenylephrine hydrochloride and $0.5 \%$ tropicamide (Santen Pharmaceutical Co., Ltd., Tokyo, Japan) during laser treatment, CFP, and FA

\subsection{Hydrogen Inhalation}

A transparent airtight acrylic box $(20 \times 18 \times 15 \mathrm{~cm}$, length $\times$ width $\times$ height $)$ with an outflow only fan on the top was set as the inhalation chamber (Figure 7). Hydrogen and an oxygen mixture gas ( $67 \%$ hydrogen mixed with $33 \%$ oxygen) produced from deionized water by electrolysis with a hydrogen/oxygen generator (model AMS-H-03; Asclepius Meditec Co., Ltd., Shanghai, China) was directly introduced into the inhalation chamber at a rate of $3 \mathrm{~L} / \mathrm{min}$. Nitrogen gas was also applied and adjusted the oxygen concentration to $21 \%$. The inhalation chamber was flushed $30 \mathrm{~min}$ in advance with experimental gas to replace the room air inside. Animals needing hydrogen inhalation (group 3, 4, and 5) received the mixture of $21 \%$ oxygen, $42 \%$ hydrogen, and $37 \%$ nitrogen gas, according to different group protocols since Day 1 as pretreatment. The inhalation was enhanced to a continuous 8 h on Day 5 just after laser treatment in all three groups $(3,4$, and 5$)$. The hydrogen inhalation was then set back to initial protocols since Day 6 and continued after Day 15, the end of the experiment.

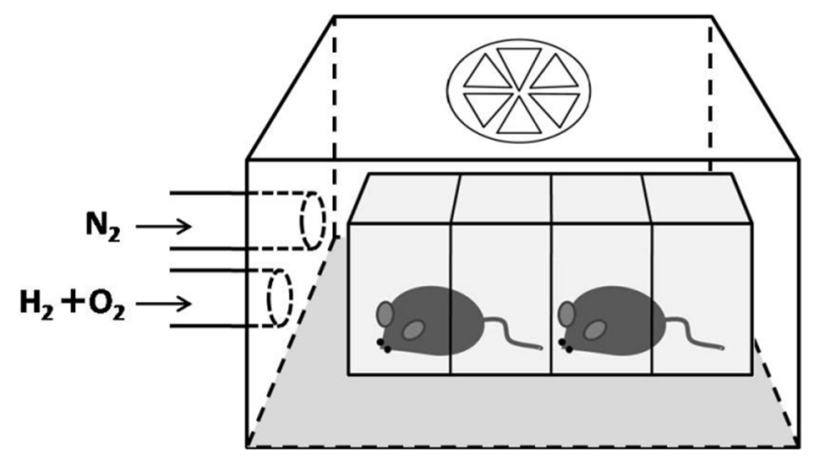

Figure 7. The setting of the inhalation chamber.

\subsection{Laser-Induced CNV Model}

Laser photocoagulation was performed on Day 5 to induce CNV as previously reported $[49,50]$. Briefly, mice were anesthetized, and the pupils were dilated in advance. Laser photocoagulation spots (100 um size, $0.15 \mathrm{~s}$ duration, $150 \mathrm{~mW}$ ) were made with $532 \mathrm{~nm}$ green laser photocoagulator (LIGHTLas 532, LIGHTMED, San Clemente, CA, USA) on each retina with a slit-lamp delivery system and a hand-held coverslip as a contact lens. Four burns were made at 3, 6, 9, and 12 o'clock positions around the optic nerve head. A production of a bubble at the time of laser irradiation, which indicated a rupture of the Bruch's membrane, suggested the effective point that induced a CNV.

\subsection{Color Fundus Photography and Fluorescene Angiography}

A Micron IV retinal imaging microscope (Phoenix Research Laboratories, Pleasanton, CA, USA) was used to monitor morphological and pathological changes in the fundus of C57BL/6J mice. Briefly, mice were anesthetized, and the pupils were dilated in advance. Each mouse was held on its side on the microscope platform and the eye was rinsed with $2 \%$ Methocel gel (OmniVision, SA, Neuhausen, Switzerland). After CFP was performed, 
fluorescein $(10 \% ; 0.05 \mathrm{~mL})$ was used for FA examination through IP injection. Serial images and videos were then collected.

Two retinal specialists (Liang and Chang) evaluated the angiograms for FA grading evaluation in a blinded manner using a grading system [51], where Grade $1=$ no hyperfluorescence; Grade 2 = hyperfluorescence without leakage; Grade 3 = hyperfluorescence in the early or middle phase and leakage in the late phase; and Grade $4=$ bright hyperfluorescence in the transit and leakage in the late phase beyond the treated areas. Subretinal hemorrhages seldom occurred during laser photocoagulation and resulted in fluorescein blockage during FA. This situation would influence the evaluation and these laser spots were excluded from FA grading evaluation to avoid significant bias. Total grades were analyzed for statistical significance.

\subsection{Histology and Immunofluorescence Staining}

Mice were euthanized on Day 15. Both eyes of each mouse were enucleated and rapidly frozen in embedding medium prior to sectioning. The optic nerve parallel to the sagittal plane at the laser photocoagulation position was selected, and slices with a thickness of 4.0 um were prepared continuously. The sections were stained with HE, observed, and photographed using a light microscope (EVOS M7000 Imaging System, Thermo Fisher, Waltham, MA, USA).

Cryosections for immunofluorescence staining were thawed, air-dried, and fixed in $10 \%$ paraformaldehyde with $0.3 \%$ TritonX-100 at room temperature for $1 \mathrm{~h}$. Immunofluorescence staining was performed according to the manufacturer's instructions. Next, the sections were washed in PBS 3 times for $5 \mathrm{~min}$. Then, the sections were incubated with pVEGFR primary antibodies (\#3817, Cell Signaling, Danvers, MA, USA) at a 1:100 dilution overnight at $4{ }^{\circ} \mathrm{C}$. The slides were washed with PBS 3 times for $5 \mathrm{~min}$ and incubated with an Alexa Fluor 594-conjugated goat anti-rabbit IgG (H + L) secondary antibodies (\#8889, Cell Signaling, Danvers, MA, USA) at 1:500 dilution for $2 \mathrm{~h}$ at room temperature. The nuclei were stained with $100 \mathrm{ng} / \mathrm{mL}$ DAPI for $10 \mathrm{~min}$. The sections were washed with PBS between these incubations. Finally, the sections were mounted and examined and captured with a fluorescence microscope (EVOS M7000 Imaging System, Thermo Fisher, Waltham, MA, USA).

\subsection{Quantitative Real-Time Polymerase Chain Reaction ( $q R T-P C R$ ) to Measure Transcription Levels}

Animals were sacrificed on day 15 and both eyes of each mouse were enucleated for qRT-PCR. Total RNA of each eye was isolated using the total RNA Isolation kit (GeneDireX, Inc., Taiwan) according to the manufacturer's instructions and reverse-transcribed into cDNA using iScript. The qPCR was performed using the StepOnePlus. Real-Time PCR System (Applied Biosystems, Foster City, CA, US) with SYBR green (Applied Biosystems, Foster City, CA, US). Primers for determining the expression of genes encoding hypoxia-inducible factor 1 alpha (HIF-1 $\alpha$ ), VEGF, tumor necrosis factor alpha (TNF- $\alpha$ ), and interlukin-6 (IL-6) are listed in Table 1.

Table 1. Primers of reverse transcription PCR analysis for genes.

\begin{tabular}{cccc}
\hline Primer & Primer Sequence $\left(\mathbf{5}^{\prime} \mathbf{- 3}^{\prime}\right)$ & Primer Sequence $\mathbf{( 3}^{\prime} \mathbf{- 5}^{\prime} \mathbf{)}$ & Product Length $\mathbf{( b p )}^{\prime}$ \\
\hline HIF-1 $\alpha$ & CCAGCAGACCCAGTTACAGA & TGAGTGCCACTGTATGCTGA & 20 \\
VEGF & CTGCTGTAACGATGAAGCCCTG & GCTGTAGGAAGCTCATCTCTCC & 22 \\
TNF- $\alpha$ & GGTGCCTATGTCTCAGCCTCTTTT & GCCATAGAACTGATGAGAGGGAG & 23 \\
IL-6 & AGTTGCCTTCTTGGGACTGA & TCCACGATTTCCCAGAGAAC & 20 \\
\hline
\end{tabular}




\subsection{Statistical Analysis}

Statistically significant differences between groups were determined using one-way analysis of variance (ANOVA) with MedCalc software. A $p$-value $<0.05$ was considered statistically significant.

\section{Conclusions}

In summary, our study revealed the bio-characteristics of hydrogen gas and its influences in CNV. The effect was achieved by suppression of both the VEGF pathway and inflammatory chemokines.

Anti-VEGF is the main clinical treatment for neovascular AMD at present, despite cases of non-responsiveness and disease recurrences remaining unsolved problems. The present study provided evidence for hydrogen inhalation as an ancillary candidate in preventing and modulating neovascular AMD via multiple pathways.

Author Contributions: Conceptualization, X.-H.Z., P.-C.L. and C.-F.H.; data curation, I.-C.L., Y.-J.H. and D.-C.C.; funding acquisition, W.-C.K.; investigation, Y.-J.H. and C.-F.H.; methodology, I.-C.L., Y.-J.H., Y.-R.L., Y.-H.C., X.-H.Z., P.-C.L. and C.-F.H.; resources, W.-C.K. and C.-F.H.; writing-original draft, W.-C.K., D.-C.C. and C.-F.H.; writing-review and editing, I.-C.L., D.-C.C. and C.-F.H. All authors have read and agreed to the published version of the manuscript.

Funding: This work was supported by research grants from Ministry of Science and Technology (MOST110-2320-B-030-004-MY3) and the Cathay General Hospital (109-CGH-FJU-03) in Taiwan.

Institutional Review Board Statement: All animal experiments in this study were approved by the Institutional Animal Care and Use Committee of Fu Jen Catholic University (approval \#A10964). The principles of the 3Rs (Re-placement, Reduction, and Refinement) were followed to optimize the experimental design.

Informed Consent Statement: Not applicable.

Data Availability Statement: Not applicable.

Acknowledgments: The authors wish to thank for technical assistance of Asclepius Meditec Co., Ltd., Shanghai, China, and Tsung Cho Chang Laboratory, College of Medicine, Fu Jen Catholic University, Taiwan.

Conflicts of Interest: The authors declare no conflict of interest.

\section{References}

1. Apte, R.S. Age-Related Macular Degeneration. N. Engl. J. Med. 2021, 385, 539-547. [CrossRef] [PubMed]

2. Wong, W.L.; Su, X.; Li, X.; Cheung, C.M.G.; Klein, R.; Cheng, C.Y.; Wong, T.Y. Global prevalence of age-related macular degeneration and disease burden projection for 2020 and 2040: A systematic review and meta-analysis. Lancet Glob. Health 2014, 2, e106-e116. [CrossRef]

3. Murray, C.J.L.; Vos, T.; Lozano, R.; Naghavi, M.; Flaxman, A.D.; Michaud, C.; Ezzati, M.; Shibuya, K.; Salomon, J.A.; Abdalla, S.; et al. Disability-adjusted life years (DALYs) for 291 diseases and injuries in 21 regions, 1990-2010: A systematic analysis for the Global Burden of Disease Study 2010. Lancet 2013, 380, 2197-2223. [CrossRef]

4. Vinding, T. Age-related macular degeneration. Macular changes, prevalence and sex ratio. Acta Ophthalmol. 2009, 67, 609-616. [CrossRef] [PubMed]

5. Rudnicka, A.R.; Jarrar, Z.; Wormald, R.; Cook, D.G.; Fletcher, A.; Owen, C.G. Age and Gender Variations in Age-related Macular Degeneration Prevalence in Populations of European Ancestry: A Meta-analysis. Ophthalmology 2012, 119, 571-580. [CrossRef]

6. Yang, X.; Chen, H.; Zhang, T.; Yin, X.; Man, J.; He, Q.; Lu, M. Global, regional, and national burden of blindness and vision loss due to common eye diseases along with its attributable risk factors from 1990 to 2019: A systematic analysis from the global burden of disease study 2019. Aging 2021, 13, 19614-19642. [CrossRef] [PubMed]

7. Ling, C.N.Y.; Lim, S.C.; Jonas, J.B.; Sabanayagam, C. Obesity and risk of age-related eye diseases: A systematic review of prospective population-based studies. Int. J. Obes. 2021, 45, 1863-1885. [CrossRef] [PubMed]

8. Roddy, G.W. Metabolic syndrome and the aging retina. Curr. Opin. Ophthalmol. 2021, 32, 280-287. [CrossRef] [PubMed]

9. Klein, R.; Peto, T.; Bird, A.; VanNewkirk, M.R. The epidemiology of age-related macular degeneration. Am. J. Ophthalmol. 2004, 137, 486-495. [CrossRef] 
10. Age-Related Eye Disease Study Research Group A Randomized, Placebo-Controlled, Clinical Trial of High-Dose Supplementation With Vitamins C and E, Beta Carotene, and Zinc for Age-Related Macular Degeneration and Vision Loss. Arch. Ophthalmol. 2001, 119, 1417-1436. [CrossRef]

11. Age-Related Eye Disease Study 2 Research Group Lutein + Zeaxanthin and Omega-3 Fatty Acids for Age-Related Macular Degeneration. JAMA 2013, 309, 2005-2015. [CrossRef] [PubMed]

12. E Clemons, T.; Milton, R.C.; Klein, R.; Seddon, J.M.; Ferris, F. Age-Related Eye Disease Study Research Group Risk Factors for the Incidence of Advanced Age-Related Macular Degeneration in the Age-Related Eye Disease Study (AREDS): AREDS report no. 19. Ophthalmology 2005, 112, 533-539.e1. [CrossRef]

13. A Chapman, N.; Jacobs, R.J.; Braakhuis, A.J. Role of diet and food intake in age-related macular degeneration: A systematic review. Clin. Exp. Ophthalmol. 2019, 47, 106-127. [CrossRef] [PubMed]

14. Qazi, Y.; Maddula, S.; Ambati, B.K. Mediators of ocular angiogenesis. J. Genet. 2009, 88, 495-515. [CrossRef] [PubMed]

15. Schwesinger, C.; Yee, C.; Rohan, R.M.; Joussen, A.M.; Fernandez, A.; Meyer, T.N.; Poulaki, V.; Ma, J.J.; Redmond, T.M.; Liu, S.; et al. Intrachoroidal Neovascularization in Transgenic Mice Overexpressing Vascular Endothelial Growth Factor in the Retinal Pigment Epithelium. Am. J. Pathol. 2001, 158, 1161-1172. [CrossRef]

16. Zachary, I. Neuroprotective Role of Vascular Endothelial Growth Factor: Signalling Mechanisms, Biological Function, and Therapeutic Potential. Neurosignals 2005, 14, 207-221. [CrossRef] [PubMed]

17. Sene, A.; Chin-Yee, D.; Apte, R.S. Seeing through VEGF: Innate and adaptive immunity in pathological angiogenesis in the eye. Trends Mol. Med. 2015, 21, 43-51. [CrossRef] [PubMed]

18. Ohsawa, I.; Ishikawa, M.; Takahashi, K.; Watanabe, M.; Nishimaki, K.; Yamagata, K.; Katsura, K.-I.; Katayama, Y.; Asoh, S.; Ohta, S. Hydrogen acts as a therapeutic antioxidant by selectively reducing cytotoxic oxygen radicals. Nat. Med. 2007, 13, 688-694. [CrossRef] [PubMed]

19. Long, P.; Yan, W.; He, M.; Zhang, Q.; Wang, Z.; Li, M.; Xue, J.; Chen, T.; An, J.; Zhang, Z. Protective effects of hydrogen gas in a rat model of branch retinal vein occlusion via decreasing VEGF- $\alpha$ expression. BMC Ophthalmol. 2019, 19, 112. [CrossRef] [PubMed]

20. Wang, R.; Wu, J.; Chen, Z.; Xia, F.; Sun, Q.; Liu, L. Postconditioning with inhaled hydrogen promotes survival of retinal ganglion cells in a rat model of retinal ischemia/reperfusion injury. Brain Res. 2016, 1632, 82-90. [CrossRef]

21. Yan, W.; Chen, T.; Long, P.; Zhang, Z.; Liu, Q.; Wang, X.; An, J.; Zhang, Z. Effects of Post-Treatment Hydrogen Gas Inhalation on Uveitis Induced by Endotoxin in Rats. Med Sci. Monit. 2018, 24, 3840-3847. [CrossRef] [PubMed]

22. Fleckenstein, M.; Keenan, T.D.L.; Guymer, R.H.; Chakravarthy, U.; Schmitz-Valckenberg, S.; Klaver, C.C.; Wong, W.T.; Chew, E.Y. Age-related macular degeneration. Nat. Rev. Dis. Prim. 2021, 7, 1-25. [CrossRef]

23. Killingsworth, M.C. Angiogenesis in early choroidal neovascularization secondary to age-related macular degeneration. Graefe's Arch. Clin. Exp. Ophthalmol. 1995, 233, 313-323. [CrossRef] [PubMed]

24. Grossniklaus, H.E.; Green, W. Choroidal neovascularization. Am. J. Ophthalmol. 2004, 137, 496-503. [CrossRef] [PubMed]

25. Spaide, R.F. Rationale for Combination Therapies for Choroidal Neovascularization. Am. J. Ophthalmol. 2006, 141, 149-156. [CrossRef]

26. Campa, C.; Costagliola, C.; Incorvaia, C.; Sheridan, C.; Semeraro, F.; De Nadai, K.; Sebastiani, A.; Parmeggiani, F. Inflammatory Mediators and Angiogenic Factors in Choroidal Neovascularization: Pathogenetic Interactions and Therapeutic Implications. Mediat. Inflamm. 2010, 2010, 1-14. [CrossRef] [PubMed]

27. Lopez, P.F.; Sippy, B.D.; Lambert, H.M.; Thach, A.B.; Hinton, D.R. Transdifferentiated retinal pigment epithelial cells are immunoreactive for vascular endothelial growth factor in surgically excised age-related macular degeneration-related choroidal neovascular membranes. Investig. Ophthalmol. Vis. Sci. 1996, 37, 855-868.

28. Ishibashi, T.; Hata, Y.; Yoshikawa, H.; Nakagawa, K.; Sueishi, K.; Inomata, H. Expression of vascular endothelial growth factor in experimental choroidal neovascularization. Graefe's Arch. Clin. Exp. Ophthalmol. 1997, 235, 159-167. [CrossRef]

29. Marneros, A.G.; Fan, J.; Yokoyama, Y.; Gerber, H.P.; Ferrara, N.; Crouch, R.K.; Olsen, B.R. Vascular Endothelial Growth Factor Expression in the Retinal Pigment Epithelium Is Essential for Choriocapillaris Development and Visual Function. Am. J. Pathol. 2005, 167, 1451-1459. [CrossRef]

30. Sheridan, C.M.; Pate, S.; Hiscott, P.; Wong, D.; Pattwell, D.M.; Kent, D. Expression of hypoxia-inducible factor-1 $\alpha$ and $-2 \alpha$ in human choroidal neovascular membranes. Graefe's Arch. Clin. Exp. Ophthalmol. 2009, 247, 1361-1367. [CrossRef] [PubMed]

31. Vadlapatla, A.D.V.A.A.K.M.R.K.; Vadlapudi, A.D.; Mitra, A.K. Hypoxia-Inducible Factor-1 (HIF-1): A Potential Target for Intervention in Ocular Neovascular Diseases. Curr. Drug Targets 2013, 14, 919-935. [CrossRef] [PubMed]

32. Brijesh, T.; Shorya, A. Macular Atrophy Progression and 7-Year Vision Outcomes in Subjects From the ANCHOR, MARINA, and HORIZON Studies: The SEVEN-UP Study. Am. J. Ophthalmol. 2015, 162, 200. [CrossRef]

33. Krebs, I.; Glittenberg, C.; Ansari-Shahrezaei, S.; Hagen, S.; Steiner, I.; Binder, S. Non-responders to treatment with antagonists of vascular endothelial growth factor in age-related macular degeneration. Br. J. Ophthalmol. 2013, 97, 1443-1446. [CrossRef] [PubMed]

34. Amoaku, W.M.; Chakravarthy, U.; Gale, R.; Gavin, M.; Ghanchi, F.; Gibson, J.M.; Harding, S.P.; Johnston, R.L.; Kelly, S.P.; Lotery, A.J.; et al. Defining response to anti-VEGF therapies in neovascular AMD. Eye 2015, 29, 721-731. [CrossRef]

35. Apte, R.S.; Richter, J.; Herndon, J.; A Ferguson, T. Macrophages Inhibit Neovascularization in a Murine Model of Age-Related Macular Degeneration. PLoS Med. 2006, 3, e310. [CrossRef] [PubMed] 
36. Outtz, H.H.; Tattersall, I.; Kofler, N.M.; Steinbach, N.; Kitajewski, J. Notch1 controls macrophage recruitment and Notch signaling is activated at sites of endothelial cell anastomosis during retinal angiogenesis in mice. Blood 2011, 118, 3436-3439. [CrossRef] [PubMed]

37. Sakurai, E.; Anand, A.; Ambati, B.K.; Van Rooijen, N.; Ambati, J. Macrophage Depletion Inhibits Experimental Choroidal Neovascularization. Investig. Ophthalmol. Vis. Sci. 2003, 44, 3578-3585. [CrossRef] [PubMed]

38. E Grossniklaus, H.; Ling, J.X.; Wallace, T.M.; Dithmar, S.; Lawson, D.H.; Cohen, C.; Elner, V.; Elner, S.G.; Sternberg, P. Macrophage and retinal pigment epithelium expression of angiogenic cytokines in choroidal neovascularization. Mol. Vis. 2002, 8, 119-126.

39. Leibovich, S.J.; Polverini, P.J.; Shepard, H.M.; Wiseman, D.; Shively, V.P.; Nuseir, N. Macrophage-induced angiogenesis is mediated by tumour necrosis factor- $\alpha$. Nat. Cell Biol. 1987, 329, 630-632. [CrossRef] [PubMed]

40. Espinosa-Heidmann, D.G.; Suner, I.J.; Hernandez, E.P.; Monroy, D.; Csaky, K.G.; Cousins, S.W. Macrophage Depletion Diminishes Lesion Size and Severity in Experimental Choroidal Neovascularization. Investig. Ophthalmol. Vis. Sci. 2003, 44, 3586-3592. [CrossRef] [PubMed]

41. Joussen, A.M.; Poulaki, V.; Mitsiades, N.; Kirchhof, B.; Koizumi, K.; Döhmen, S.; Adamis, A.P. Nonsteroidal anti-inflammatory drugs prevent early diabetic retinopathy via TNF- $\alpha$ suppression. FASEB J. 2002, 16, 438-440. [CrossRef] [PubMed]

42. Koizumi, K.; Poulaki, V.; Doehmen, S.; Welsandt, G.; Radetzky, S.; Lappas, A.; Kociok, N.; Kirchhof, B.; Joussen, A.M. Contribution of TNF- $\alpha$ to Leukocyte Adhesion, Vascular Leakage, and Apoptotic Cell Death in Endotoxin-Induced Uveitis In Vivo. Investig. Ophthalmol. Vis. Sci. 2003, 44, 2184-2191. [CrossRef] [PubMed]

43. Ghasemi, H. Roles of IL-6 in Ocular Inflammation: A Review. Ocul. Immunol. Inflamm. 2018, 26, 37-50. [CrossRef] [PubMed]

44. Seddon, J.M.; George, S.; Rosner, B.; Rifai, N. Progression of Age-Related Macular Degeneration. Arch. Ophthalmol. 2005, 123, 774-782. [CrossRef] [PubMed]

45. Cui, W.; Zhang, H.; Liu, Z.-L. Interleukin-6 receptor blockade suppresses subretinal fibrosis in a mouse model. Int. J. Ophthalmol. 2014, 7, 194-197. [CrossRef] [PubMed]

46. Sato, K.; Takeda, A.; Hasegawa, E.; Jo, Y.-J.; Arima, M.; Oshima, Y.; Ryoji, Y.; Nakazawa, T.; Yuzawa, M.; Nakashizuka, H.; et al. Interleukin-6 plays a crucial role in the development of subretinal fibrosis in a mouse model. Immunol. Med. 2018, 41, 23-29. [CrossRef] [PubMed]

47. Li, H.; Chen, O.; Ye, Z.; Zhang, R.; Hu, H.; Zhang, N.; Huang, J.; Liu, W.; Sun, X. Inhalation of high concentrations of hydrogen ameliorates liver ischemia/reperfusion injury through A 2A receptor mediated PI3K-Akt pathway. Biochem. Pharmacol. 2017, 130, 83-92. [CrossRef] [PubMed]

48. Cui, J.; Chen, X.; Zhai, X.; Shi, D.; Zhang, R.; Zhi, X.; Li, X.; Gu, Z.; Cao, L.; Weng, W.; et al. Inhalation of water electrolysis-derived hydrogen ameliorates cerebral ischemia-reperfusion injury in rats-A possible new hydrogen resource for clinical use. Neurosci. 2016, 335, 232-241. [CrossRef] [PubMed]

49. Iwanishi, H.; Fujita, N.; Tomoyose, K.; Okada, Y.; Yamanaka, O.; Flanders, K.C.; Saika, S. Inhibition of development of laserinduced choroidal neovascularization with suppression of infiltration of macrophages in Smad3-null mice. Lab. Investig. 2016, 96, 641-651. [CrossRef] [PubMed]

50. Park, J.R.; Choi, W.; Hong, H.K.; Kim, Y.; Hwang, Y.; Woo, S.J.; Oh, W.-Y. Imaging Laser-Induced Choroidal Neovascularization in the Rodent Retina Using Optical Coherence Tomography Angiography. Investig. Ophthalmol. Vis. Sci. 2016, 57, 331-340. [CrossRef]

51. Onami, H.; Nagai, N.; Kaji, H.; Nishizawa, M.; Sato, Y.; Osumi, N.; Nakazawa, T.; Abe, T. Transscleral Sustained Vasohibin1 Delivery by a Novel Device Suppressed Experimentally-Induced Choroidal Neovascularization. PLoS ONE 2013, 8, e58580. [CrossRef] [PubMed] 